\title{
Sample Preparation Techniques for Microhistological Analysis
}

\author{
JERRY L. HOLECHEK
}

\section{Methods}

Fecal samples from cows (summer), horses, and deer (winter) were collected from desert range in south central New Mexico. In addition, two sample mixtures were prepared from desert species collected in the fall. Prepared diet sample 1 contained $11.11 \%$ by weight of each of three species of grasses, forbs and shrubs. Sample 2 contained current year's growth of eight shrub species and two desert grass species. Shrubs comprised $95 \%$ of this diet by weight; grasses 5\%. Shrub material in both prepared diet samples was primarily twigs and buds that did not exceed $2 \mathrm{~cm}$ in length.

All material was dried, then ground through a micro-Wiley mill with a $1-\mathrm{mm}$ sieve prior to treatment. The samples were then subjected to five treatments: (1) soaking overnight in water, (2) soaking overnight in formalin acetic alcohol ( 85 parts $70 \%$ alcohol, 10 parts $40 \%$ formaldehyde, 5 parts glacial acetic acid), (3) soaking overnight in chloral benzene alcohol (40\% chloroform, $50 \%$ ethanol, $10 \%$ benzene), (4) soaking in $0.05 \mathrm{~m} \mathrm{NaOH}$ for 30 minutes, or (5) soaking in sodium hypochlorite (domestic bleach) for 30 minutes. All sample material was boiled in distilled water for $2 \mathrm{~min}$. following treatment application. Slides were prepared using the procedure of Sparks and Malechek (1968). Hertwig's clearing and Hoyer's mounting solutions were used in preparation of all slides.

Five slides were prepared for each sample/treatment combination, and 20 microscope fields per slide were observed. Two trained observers read each set of five slides for each sample/treatment combination. The number of identifiable and nonidentifiable fragments were recorded in each microscope field. Only fragments permitting positive identification were considered identifiable. When only a portion of a particle was observed in a field and that particle could not be identified, the slide was moved so the entire particle could be observed. Cow, horse, and deer diet sample fragments were placed into two categories: (1) grasses and (2) forbs and shrubs. Prepared diet sample fragments were placed into three categories: (1) grasses, (2) forbs, and (3) shrubs. The percent by weight of these categories in the diet was determined by dividing the number of identifiable fragments for each category by the total number of identifiable fragments of all plant species and then multiplying this number by 100 (Sparks and Malechek 1968). A factorial, randomized complete block analysis of variance with observers as blocks and diets and treatments as factors was used to analyze all data (Steel and Torrie 1960). Duncan's multiple range test was used to rank treatment means.

\section{Results and Discussion}

Bleach and $0.05-\mathrm{m} \mathrm{NaOH}$ treatments resulted in a significantly higher $(P<.05)$ ratio of identifiable to nonidentifiable fragments than the other three treatments (Table 1). The ratio of identifiable

Author is assistant professor of range ecology, Department of Animal and Range Sciences, New Mexico State University, Las Cruces, New Mexico 88003.

This report is Journal Article 767, Agricultural Experiment Station, New Mexico State Univ., Las Cruces 88003

Manuscript received May 28, 1980.

Table 1. Ratio of the number of identifiable to nonidentifiable fragments in the diet samples for the five treatments.

\begin{tabular}{lcccccc}
\hline \hline Animal'12 & Control & $\begin{array}{c}\text { Formalin acetic } \\
\text { acid }\end{array}$ & $\begin{array}{c}\text { Chloral benzene } \\
\text { alcohol }\end{array}$ & $0.05 \mathrm{~m} \mathrm{NaOH}$ & Bleach & $\bar{X}$ \\
\hline Cow (Summer) & 0.6 & 0.8 & 0.7 & 1.0 & 1.5 & $0.9^{\mathrm{a}}$ \\
Horse (Winter) & 0.5 & 0.6 & 0.7 & 1.3 & 1.5 & $0.9^{\mathrm{a}}$ \\
Deer (Winter) & 0.1 & 0.1 & 0.1 & 0.2 & 0.3 & $0.2^{c}$ \\
Prepared Diet 1 & 0.2 & 0.2 & 0.3 & 0.9 & 1.0 & $0.5^{\mathrm{b}}$ \\
Prepared Diet 2 & $<0.1$ & $<0.1$ & 0.1 & 0.2 & 0.2 & $0.1^{c}$ \\
\hline
\end{tabular}
$\bar{X}$
$0.3^{\mathrm{b}}$
$0.4^{b}$
$0.4^{\mathrm{b}}$
$0.7^{a}$
$0.9^{\mathrm{a}}$

'Treatments with different letters are significantly different $(R<.05)$ using Duncan's multiple range test.

${ }^{2}$ Hertwig's clearing solution was used in all treatments. 
to nonidentifiable fragments was significantly different $(\boldsymbol{P}<.01)$ among diet samples. Data in Table 2 show that the proportion of grass was significantly $(P<.05)$ decreased by application of sodium hydroxide or bleach. When data for the two prepared diet samples were pooled, the browse component was significantly increased $(P<.05)$ by application of either sodium hydroxide or bleach. However the forb component of diet 1 was unaffected. The lower percentage grass in diet samples as a result of either sodium hydroxide or bleach application is attributed to a higher proportion of identifiable shrub fragments as the result of pigment removal. Application of these two treatments greatly improved the estimation of grass, forb, and shrub components of the two prepared diets. However, grass was overestimated in prepared diet sample 2 by a factor 2.2 to 2.6 even when either sodium hydroxide or bleach were applied.

The data from this study show that sample preparation for microhistological analysis by either soaking in $0.05 \mathrm{~m}$ sodium hydroxide or bleach in conjunction with use of Hertwig's clearing solution can improve the number of identifiable fragments compared to use of only Hertwig's clearing solution. Application of either of these two treatments may also improve the accuracy of diet estimation. Williams (1969) reported that bleach greatly improved the number of fragments identifiable in fecal samples. The use of sodium hydroxide has been found to improve the accuracy of diet estimation when microhistological analysis is used (Vavra and Holechek 1980). However, these two treatments may result in destruction of some plant materials. The author has found

Table 2. The percent by weight of grasses, forbs, and shrubs in diet samples for the five treatments.

\begin{tabular}{|c|c|c|c|c|c|}
\hline Animal $^{12}$ & Control & $\begin{array}{l}\text { Formalin } \\
\text { acetic } \\
\text { acid }\end{array}$ & $\begin{array}{l}\text { Choral } \\
\text { benzene } \\
\text { alcohol }\end{array}$ & $\begin{array}{l}0.05 \mathrm{~m} \\
\mathrm{NaOH}\end{array}$ & Bleach \\
\hline $\begin{array}{l}\text { Grasses (Mean) } \\
\text { Cow (Summer) } \\
\text { Horse (Winter) } \\
\text { Deer (Winter) } \\
\text { Prepared Diet } 1 \\
\text { Prepared Diet } 2\end{array}$ & $\begin{array}{l}70 \\
85 \\
21 \\
54 \\
28 \\
52\end{array}$ & $\begin{array}{l}69 \\
82 \\
18 \\
50 \\
24 \\
49^{2}\end{array}$ & $\begin{array}{l}70 \\
83 \\
19 \\
48 \\
26 \\
49^{a}\end{array}$ & $\begin{array}{l}67 \\
82 \\
14 \\
35 \\
13 \\
43^{b}\end{array}$ & $\begin{array}{r}67 \\
80 \\
6 \\
32 \\
11 \\
39^{b}\end{array}$ \\
\hline $\begin{array}{l}\text { Forbs (Mean) } \\
\text { Prepared Diet } 1 \\
\text { Prepared Diet } 2\end{array}$ & $\frac{29}{29}$ & $\frac{28}{28}$ & $\frac{29}{29}$ & $\frac{32}{32}$ & $\frac{32}{32}$ \\
\hline $\begin{array}{l}\text { Shrubs (Mean) } \\
\text { Prepared (Diet 1) } \\
\text { Prepared (Diet 2) }\end{array}$ & $\begin{array}{l}17 \\
72 \\
45^{\mathrm{c}}\end{array}$ & $\begin{array}{l}22 \\
76 \\
49^{c}\end{array}$ & $\begin{array}{l}23 \\
74 \\
49^{c}\end{array}$ & $\begin{array}{l}33 \\
87 \\
60^{\mathrm{b}}\end{array}$ & $\begin{array}{l}36 \\
89 \\
68^{\mathrm{a}}\end{array}$ \\
\hline
\end{tabular}

ITreat ments with different letters are significantly different $(P<.05)$ using Duncan's Multiple Range test.

${ }^{2}$ Hertwig's clearing solution was used in all treatments. that bleach destroys lichen fragments. Therefore it appears advisable to analyze diet samples both with and without sodium hydroxide or bleach application prior to making a decision regarding use.

The ratio between identifiable and nonidentifiable fragments varied with the botanical composition of the diet sample, and was influenced by the method of sample preparation. Havstad and Donart (1978) reported that ratios of identifiable to nonidentifiable fragments were not equal between grasses and forbs. Data from these two studies suggest that results from microhistological analysis must be interpreted with caution, particularly when diet samples are high in woody plant material. Accuracy may be further reduced for fecal samples because of differential digestion between plant species (Vavra and Holechek 1980, Dearden et al. 1975). These two problems can be solved with the use of prepared diet samples and microdigestion techniques as discussed by Vavra and Holechek (1980) and Dearden et al. (1975).

\section{Literature Cited}

Baumgartner, L.L., and A.C. Martin. 1939. Plant histology as an aid in squirrel food-habitat studies. J. Wildl. Manage. 3:266-268.

Croker, Barbara H. 1959. A method of estimating the botanical composition of the diet of sheep. New Zeal. J. Agr. Res. 2:72-85.

Dearden, Boyd L., Robert E. Pegau, and Richard M. Hansen. 1975. Precision of microhistological estimates of ruminant food habits. J. Wildl. Manage. 39:402-407.

Dusi, J.L. 1949. Methods for the determination of food habits by plants microtechniques and histology and their application to cottontail rabbit food habits. J. Wildl. Manage. 13:295-298.

Griffiths, M., and R. Barker. 1966. The plants eaten by sheep and by kangaroos grazing together in a paddock in southwestern Queensland. C.S.I.R.O. Wildl. Res. 11:145-167.

Havstad, K.M., and G.B. Donart. 1978. The microhistological technique: testing two central assumptions in southecntral New Mexico. J. Range Manage. 31:469-470.

Martin, D.J. 1954. Features of plant cuticle: an aid to the analysis of the natural diet of grazing animals, with special reference to Scottish hill sheep. Trans. Proc. Bot. Soc. Edinb. 36:278-288.

Metcalfe, C.R. 1960. Anatomy of monocotyled ons. 1. Graminease. Clarendon Press, Oxford. 731 p.

Sparks, D.R., and J.C. Malechek. 1968. Estimating percentage dry weight in diets using a microscopic technique. J. Range Manage. 21:264-265.

Stewart, D.R.M., 1965. The epidermal characters of grasses with special reference to East African plains species. Bot. Jaarb. 84:63-74.

Stewart, D.R.M. 1967. Analysis of plant epidermis in faeces: a technique for studying food preferences of grazing herbivores. J. Applied Ecol. 4:83-111.

Storr, G.M. 1961. Microscopic analysis of faeces, a technique for ascertaining the diet of herbivorous mammals. Austral. J. Biol. Sci. 14:157-164.

Vavra, M., and J.L. Holechek. 1980. Factors influencing microhistological analysis of herbivore diets. J. Range Manage. 33:371-374.

Ward, A.L. 1970. Stomach content and fecal analysis: methods of forage identification. In: Range and Wildlife Habitat Evaluation-A Res. Symp. U.S. Dep. Agr. Forest Service Misc. Pub. No. 1147. 220 p.

Williams, Owen B. 1969. An improved technique for identification of plant fragments in herbivore feces. J. Range Manage. 22:51-52. 